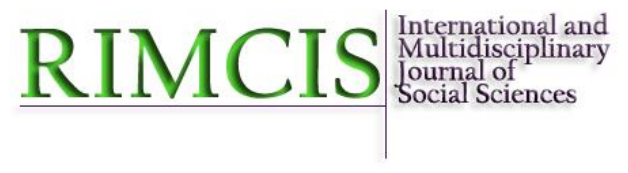

Hipatia Press

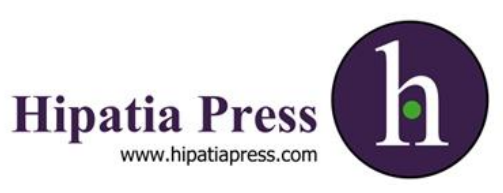

Instructions for authors, subscriptions and further details:

http://rimcis.hipatiapress.com

\title{
El Andalucismo de la Asamblea de Ronda a la Guerra Civil (1918-1936): Aplicación de las Propuestas de Miroslav Hroch
}

Cristian Rodríguez Mesa ${ }^{1}$

1) Universidad de Cádiz, España

Date of publication: November $30^{\text {th }}, 2018$

Edition period: November 2018 - February 2019

To cite this article: Rodríguez Mesa, C. (2018). El Andalucismo de la Asamblea de Ronda a la Guerra Civil (1918-1936): Aplicación de las Propuestas de Miroslav Hroch. International and Multidisciplinary Journal of Social Sciences, 7(3), 243-266. doi: 10.17583/rimcis.2018.3537

To link this article: http://doi.org/10.17583/rimcis.2018.3537

\section{PLEASE SCROLL DOWN FOR ARTICLE}

The terms and conditions of use are related to the Open Journal System and to Creative Commons Attribution License (CC-BY). 


\section{The Andalusian Nationalism from the Assembly of Ronda to the Civil War (1918-1936): An Application of Miroslav Hroch's Proposals}

Cristian Rodríguez Mesa

Universidad de Cádiz

\section{Abstract}

With this paper, we intend to explain the proposals of the Czech historian and political scientist Miroslav Hroch about the national movements of Eastern Europe and its evolution. We are going to apply them to the case of the Andalusian nationalism, with the intention of verifying if it is possible to use the different models he raises to explain the way in which patriotic agitation develops between national groups in the geographical area of Western Europe. With this objective, we have analyzed the evolution of Andalusian nationalism in its formation process as a political movement, focusing both on its discourse and objectives and on the factors that prevented it from becoming a hegemonic current in Andalusia in the period from 1918 to 1936. In this way, we want to check the validity of the scheme proposed by Hroch and delimit in what kind of evolution we could frame the case that concerns us, which, considering its failure, would be a clear example of a disintegrated type, as it did not consolidate as a mass movement.

Keywords: nationalism, Andalusia, Miroslav Hroch 


\section{El Andalucismo de la Asamblea de Ronda a la Guerra Civil (1918-1936): Aplicación de las Propuestas de Miroslav Hroch}

Cristian Rodríguez Mesa

Universidad de Cádiz

\section{Resumen}

Con este trabajo pretendemos en primer lugar explicar las propuestas del historiador y politólogo checo Miroslav Hroch sobre los movimientos nacionales de Europa oriental y su evolución para aplicarlas al caso del andalucismo, con la intención de comprobar si es posible utilizar los distintos modelos que plantea para explicar la forma en que se desarrolla la agitación patriótica entre grupos nacionales del ámbito geográfico de la Europa occidental. Con este objetivo hemos analizado la evolución del nacionalismo andaluz en su proceso de formación como movimiento político, centrándonos tanto en su discurso y objetivos como en los factores que le impidieron convertirse en una corriente hegemónica en Andalucía en el periodo que va de 1918 a 1936. De esta manera, queremos comprobar la validez del esquema propuesto por Hroch y delimitar en qué tipo de evolución podríamos encuadrar el caso que nos ocupa, que, atendiendo a su fracaso, sería un claro ejemplo de tipo desintegrado, pues no llega a consolidarse como un movimiento de masas.

Palabras clave: nacionalismo, Andalucía, Miroslav Hroch 


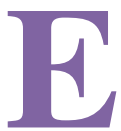

112 de septiembre de 2015 tuvo lugar en Torremolinos el XVII Congreso Nacional del Partido Andalucista, que pondría fin a la existencia de esta formación tras casi cuarenta años de historia y el fracaso consecutivo en las elecciones al Parlamento de Andalucía de 2008, 2012 y 2015 , en las cuales no obtuvo ninguna representación ${ }^{1}$. Lejos quedaban los dignos resultados electorales obtenidos en marzo de 1979 en las elecciones generales, cuando el entonces Partido Socialista de Andalucía llegó a formar grupo parlamentario en el Congreso de los Diputados. Este relativo éxito quedaría ratificado un mes después en las municipales, cuando esta formación se hace con la alcaldía de Sevilla y de algunas otras ciudades importantes como Jerez, mientras se integra en los gobiernos de coalición de izquierdas del resto de las capitales provinciales andaluzas.

Sin embargo, la fuerza de este movimiento se desvanecería rápidamente y apenas tendría la oportunidad de convertirse en determinante ante la arrolladora hegemonía de un PSOE andaluz que asumió tácticamente el discurso andalucista apostando por la figura de Rafael Escuredo (Ruiz Romero, 2018) y que ha acaparado casi sin contestación todo el entramado institucional creado en un territorio que, a comienzos de la Transición, parecía fuertemente comprometido con la lucha por la autonomía, tal y como demostraron las movilizaciones del 4 de diciembre de 1977 y la firma del Pacto de Antequera al año siguiente (Cruz Artacho, 2011). De hecho, a día de hoy el nacionalismo andaluz se ha convertido en algo testimonial y solamente pervive entre ciertos sectores de izquierda vinculados al Sindicato Andaluz de Trabajadores y a la Candidatura Unitaria de Trabajadores, en la órbita de Izquierda Unida y Podemos, ahora coaligados en la candidatura Adelante Andalucía. En cuanto a otros grupos que se definen como nacionalistas, esta vez desde una orientación ideológica más transversal, sería posible hacer referencia a pequeños partidos como Andalucía por sí o a la recientemente constituida Asamblea Nacional Andaluza, que intenta replicar a la organización equivalente catalana, aunque sin apenas notoriedad al igual que su partido vinculado, Somos Andaluces.

Esta situación de letargo del andalucismo, a cien años de su nacimiento como movimiento político en la Asamblea de Ronda, hace pensar en que ha sufrido un fracaso sin matices, aunque no en otros aspectos como la consecución de gran parte de los objetivos que se planteaban en su seno, al 
haberse logrado un alto nivel de autonomía para el territorio y la consolidación de un sentimiento generalizado de identificación de los andaluces con el mismo (CADPEA, 2018, p. 44-45). Con la finalidad de entender cómo el nacionalismo andaluz ha llegado hasta aquí, analizaremos el periodo crucial en el cual se gestó, el primer tercio del siglo XX, utilizando como herramienta teórica las propuestas del historiador $\mathrm{y}$ politólogo checo Miroslav Hroch, que estudiaremos a continuación. Una vez hecho esto, trataremos de aplicar el esquema planteado por este autor al caso del nacionalismo andaluz para luego ofrecer unas conclusiones generales que puedan explicar el estado en el que se encuentra y las razones que han conducido a ello.

\section{Las Fases de Construcción de los Movimientos Nacionales: La Propuesta de Miroslav Hroch}

Sobre la historia del nacionalismo como movimiento político contemporáneo se han publicado numerosos trabajos que han ofrecido otras tantas interpretaciones acerca de este fenómeno, desde las obras clásicas de Ernest Gellner (2001) y Benedict Anderson (1993), que configuran el paradigma modernista, hasta las propuestas de Anthony Smith (1997), catalogadas como primordialistas, pasando por las aportaciones de John Breuilly (1993), Charles Tilly (1975) o Eugen Weber (1976). Sin embargo, pese a esta notable producción sobre un tema tan importante como el nacionalismo, podemos decir que todos estos autores parten de dos principios básicos: en primer lugar, la consideración del nacionalismo como un fenómeno que no es innato a la humanidad y, en segundo lugar, la artificialidad e instrumentalización política de las identidades nacionales, lo que convierte a estas últimas en construcciones condenadas a la transformación constante e incluso a su desaparición en muchos casos (Álvarez Junco, 2016).

A la primera de estas conclusiones podemos llegar por el hecho constatado de que las naciones, tal y como las conocemos hoy, no han existido desde siempre, puesto que antes de las revoluciones liberales que tuvieron lugar en Europa no existió un movimiento como el nacionalismo que reivindicara el Estado nación como modelo ideal y hegemónico para la 
organización política de grupos humanos. No podemos perder de vista que antes de este momento habían existido una gran variedad de fórmulas que permitían esa organización, pues desde las tribus hasta los imperios podríamos encontrar modelos como el de las ciudades-Estado, el de las repúblicas, el de las confederaciones o el de las monarquías. Además, al igual que sigue ocurriendo en la actualidad, las identidades humanas se han revelado mucho más complejas, pues junto a las correspondientes a la nacionalidad conviven otros tipos de sentimientos de pertenencia tanto a niveles inferiores (familiares, locales, regionales, profesionales) como a niveles superiores (religiones y civilizaciones).

En cuanto a la segunda de estas conclusiones, debemos señalar que todos estos autores coinciden en afirmar que las naciones son construcciones recientes surgidas a raíz de los movimientos políticos nacionalistas. La finalidad de estos no sería otra que generar una idea de pertenencia colectiva en comunidades que comparten rasgos culturales, pero no están articuladas políticamente. Como hemos visto, en muchas ocasiones han sido los Estados los encargados de impulsar este tipo de movimientos mediante una serie de políticas de nacionalización de las masas, tal y como han analizado historiadores como Anne-Marie Thiesse (2010) y Eugen Weber. Sin embargo, no en todos los casos son los Estados, con sus muy diversas herramientas, los que impulsan estos procesos de construcción nacional, tal y como propone el politólogo Charles Breuilly, quien habla de la existencia de movimientos nacionalistas que plantean sus luchas como un proceso de emancipación de sus comunidades de aquellos Estados de los que forman parte y cuya unidad cuestionan.

En estos movimientos desempeñarían un papel fundamental las élites nacionalistas que, sin contar con el enorme soporte de los poderes estatales, pudieron lograr la extensión de sus ideas al resto de sus comunidades, convirtiendo el nacionalismo en un movimiento político de masas y transversal. El mayor referente en los estudios de estas élites es Miroslav Hroch (1985), quien propone un esquema de desarrollo de los movimientos nacionales en uno de sus principales trabajos, Social preconditions of national revival in Europe. De acuerdo a este esquema, sería posible advertir a grandes rasgos la existencia de tres fases en todos los movimientos nacionalistas de los pequeños países de Europa central y oriental: una 
primera fase o fase A, en la que aparece entre las élites intelectuales un nacionalismo cultural que se manifiesta en un gran interés por estudiar la lengua y la historia de ciertas comunidades, aunque sin pretensiones políticas; una segunda fase o fase $\mathrm{B}$ en la que, sin dejar de ser un movimiento de élites y por tanto minoritario, el nacionalismo pasa de las reivindicaciones culturales a las de carácter político; y una tercera fase o fase $\mathrm{C}$, en la cual el nacionalismo se extiende a las masas, haciéndose transversal y surgiendo partidos modernos que ponen en el centro del debate público las reivindicaciones de este movimiento.

Este esquema, que Hroch aplicó al estudio de distintos casos presentes en la Europa central y oriental, constituye no obstante un buen punto de partida para analizar el desarrollo de otros movimientos nacionalistas presentes en territorios localizados fuera del área donde centró su trabajo. Este sería el caso del andalucismo, que nació como fuerza política durante el reinado de Alfonso XIII y la Segunda República, pero no lograría consolidarse. Sin embargo, antes de sintetizar las propuestas de Hroch, es necesario aclarar un aspecto importante acerca de las mismas y es que no aportan una explicación novedosa ni diferentes del origen de los nacionalismos, pues, tal y como él mismo reconoció, sigue fundamentalmente las líneas del paradigma modernista:

Quan vaig començar a escriure, ja fa trenta anys, el meu llibre sobre la composició social dels líders dels moviments nacionals, no era la meua intenció formular una "teoria" sobre els orígens de les nacions. El meu propòsit era de bon tros més modest: només assajava de determinar quines circumstàncies socials afavorien una expansió reeixida de la consciencia nacional entre l'extensa massa de la població -en altres paraules, quines eren les condicions perquè reeixissin aquelles activitats que jo vaig agrupar sota el terme "agitació nacional" (Hroch, 2001, p. 33).

En cambio, lo que sí que habría que destacar es que Hroch se ha convertido en una figura fundamental para entender desde un punto de vista historiográfico y de la politología la forma en que se desarrollan estos movimientos nacionalistas y cuáles son los condicionantes sociales que favorecen este proceso en las naciones que él cataloga como menores. Es 
decir, aquellas comunidades que, formando parte de imperios multiétnicos, carecían de clases dominantes propias y disponían de una tradición lingüística y cultural propia, pero debilitada (Hroch, 2001). En este modelo encajarían tanto aquellos grupos que no habían constituido unidades políticas independientes antes de la modernización que sobrevino con el capitalismo como aquellos que desde tiempos medievales sí lo habían hecho (Hroch, 1985).

Hroch presenta también en Social preconditions of the national revival in Europe un interesante análisis comparativo de distintos movimientos nacionales de la Europa central y oriental (el noruego, el finés, el flamenco o el eslovaco entre otros). A través de él, establece lo que a su juicio son los elementos fundamentales que permiten la extensión de los procesos de agitación nacional en un contexto de transformación de las sociedades feudales en capitalistas: la movilidad social, la comunicación y, por último, el conflicto de intereses materiales, que podía alcanzar una gran importancia cuando la pertenencia a una clase social se asociaba claramente a la pertenencia a un grupo lingüístico, étnico o nacional. De ahí que fuera tan relevante la inclusión de los intereses de los diferentes grupos y clases sociales dentro de los que se podrían calificar como "nacionales", pues según este autor:

(...) quan en la fase B, el moviment nacional no era capaç d'introduir en la agitació nacional els interessos dels grups i classes específics que constituïen les nacions petites, ni d'articular aquests interessos en termes nacionals, no aconseguia reeixir. Una agitació mantinguda sota l'estendard exclusiu de la llengua, la literatura nacional o uns altres atributs superestructurals, com ara l'història, el folklore, etc., no podia per si mateixa moure els estrats populars de la població envers la causa patriòtica: la via des de la fase $\mathrm{B}$ cap a la fase $\mathrm{C}$ estava tancada o en alguns casos quedava interrompuda (Hroch, 2001, p. 24).

Normalmente, a mayor movilidad y comunicación social y, especialmente, cuando se tenían en cuenta y se sumaban reivindicaciones políticas bien extendidas entre las bases sociales, la agitación nacionalista tenía más posibilidades de alcanzar el éxito convirtiéndose en un movimiento de masas, tal y como explica en su obra principal: 
It can be assumed that national ideology is effective where it reflects (even though in a merely illusory fashion) the interests of the groups to which it makes its appeal, or contains at least in part the kind of programme which is close to their interests. It is therefore important to carry out not only an ideological but a social analysis of the patriotic groups which gradually started to adopt the national programme (Hroch, 1985, p. 12).

Por tanto, podemos ver que Hroch le otorga una importancia clave a los factores sociales que contribuyen al proceso de construcción nacional, de ahí que en los estudios que realiza sobre los grupos patrióticos haga un análisis de diversos factores para entender mejor sus intereses como son su ocupación, sus orígenes sociales y territoriales, su educación y su localización. Atendiendo a los resultados de esos estudios, este autor resalta ante todo la importancia adquirida por la burguesía y los campesinos en este proceso, pues sin estos grupos no sería posible la construcción de una nación moderna, que es definida como aquella donde hay una estructura de clases compleja (Hroch, 2001).

En otras palabras, la construcción de las naciones modernas se produce justo al mismo tiempo que la transición de la sociedad feudal a la sociedad capitalista, es decir, cuando la división estamental da paso a una división en clases sociales mientras tiene lugar la modernización e industrialización. Estos cambios generarían enormes tensiones y conflictos entre pequeños y grandes productores, siendo frecuente la identificación en las regiones que estudia Hroch la identificación de los primeros con las naciones oprimidas y de los segundos con las naciones dominantes; entre los grupos profesionales e intelectuales emergentes (lo que se viene a denominar intelligentsia), pues aquellos provenientes de las naciones oprimidas reclamaban mayor protagonismo; y, por supuesto, entre los grupos privilegiados y los populares, pues estos últimos reivindicaban la igualdad de derechos y el fin de la discriminación, exacerbándose aún más estas reclamaciones en los casos en los que formaban parte de una nación oprimida (Hroch, 2001).

Este autor divide este periodo de transición en dos estadios sucesivos, que serían un primero en el que se produce la revolución burguesa contra el absolutismo y la construcción del capitalismo y un segundo en el cual se ha 
consolidado este sistema, pero al mismo tiempo aparece el movimiento obrero. Es entonces cuando se produce la transformación de numerosas etnias en naciones, definiendo a estas últimas en un punto intermedio entre las posturas primordialistas y modernistas, pues, aunque defiende que se trata de creaciones propias de la modernidad, también asume las posturas de Anthony Smith por las cuales estas naciones necesitan de unos orígenes étnicos e históricos para consolidar una conciencia colectiva (Hroch, 1994).

Como hemos mencionado anteriormente, Hroch propone un esquema de tres fases en el desarrollo de los movimientos nacionales, que pueden sucederse a un ritmo más o menos rápido en función de las circunstancias en las que se encuentren, es decir, de los factores que hemos comentado previamente de movilidad social, comunicación e inclusión de reivindicaciones sociales en los programas nacionales.

La primera de las fases, la fase A, la denomina fase de interés académico y se caracteriza por la aparición entre algunos individuos, normalmente intelectuales, de una preocupación por el estudio y la recuperación de la lengua, la historia y la cultura de la etnia oprimida. Su interés no es político debido a que, por lo general, no cuentan con la suficiente influencia social para generar una agitación patriótica, sino que se trata de algo puramente intelectual y que, como mucho, podríamos catalogar como un tipo de patriotismo regional.

Este interés académico no haría sino crecer en la segunda fase o fase B, que Hroch define como un periodo de agitación patriótica en el que empiezan a aparecer grupos cuyo objetivo no es otro que ampliar la base social de su movimiento creando una conciencia nacional. Según este autor, se trata una fase determinante porque es cuando aparecen por primera vez reivindicaciones políticas claras, como podrían ser la igualdad de derechos de carácter lingüístico y religioso o el reconocimiento de cierto nivel de autonomía, a la vez que empiezan a formarse las élites de la nación oprimida para dar lugar a una sociedad moderna articulada en clases (Hroch, 1994). El éxito del movimiento nacional en esta fase se revela fundamental, ya que, en el caso de fracasar a la hora de extender ese sentimiento de pertenencia a la comunidad, sería difícilmente posible alcanzar la o fase $\mathrm{C}$.

Por último, la fase $\mathrm{C}$ es definida como el periodo de surgimiento de un movimiento nacional de masas, caracterizándose por ser el momento en el 


\section{Rodríguez Mesa - El Andalucismo}

que la preocupación por la conciencia nacional se ha generalizado entre la comunidad gracias a que se ha asentado una estructura organizativa sólida en todo el territorio que ocupa. Una vez alcanzada esta fase, los objetivos del movimiento nacional serán casi siempre la obtención de la soberanía y la independencia, ya sea de forma gradual y negociada o de manera insurreccional.

Sin embargo, como hemos dicho anteriormente, este esquema se reproduce de forma desigual en distintos casos, pues, dependiendo de ciertos factores, pueden suceder en estadios de desarrollo distintos. De esta forma, Hroch propone un total de cuatro tipos de movimientos nacionales en función del momento en el que se produce la transición entre las fases B y C (Hroch, 1985). En todos los modelos establece que la fase A tiene lugar en el primer estado de desarrollo, coincidiendo con el proceso de desintegración del feudalismo. Sin embargo, las fases B y C a veces se pueden dar dentro de ese mismo periodo o sucederse aquella en el primer estadio y la última en el segundo estadio, una vez que se ha consolidado el capitalismo. Incluso pueden darse casos en los que la fase B puede tener lugar de una forma muy tardía y producirse por tanto ya terminada la transición a este sistema.

El primero de los modelos de desarrollo que describe Hroch incluye dos variantes, siendo una de ellas la que denomina como "tipo integrado". En esta, la transición entre las fases A y B se produce antes de la revolución industrial, que vendría seguida por una revolución burguesa simultánea y complementaria a la transición entre las fases B y C, por lo que se trataría de movimientos que compartirían el objetivo de acabar con el Antiguo Régimen. Tras el triunfo de la revolución, al mismo tiempo burguesa y nacional, se produciría la definitiva consolidación de la nación moderna, en la cual aparecería posteriormente un movimiento obrero organizado. El esquema que propone sería, por tanto, el siguiente ${ }^{2}$ :

$$
\begin{aligned}
& \mathrm{AB} \rightarrow \mathrm{RI} \rightarrow \mathrm{RB} \rightarrow \mathrm{FN} \rightarrow \mathrm{MO} \\
& \searrow \mathrm{BC} \nearrow
\end{aligned}
$$

La segunda variante de este modelo se diferencia de la anterior solamente en que la revolución burguesa tiene lugar antes de la transición entre las fases B y C y estas van seguidas del proceso de revolución industrial. El 
esquema es, por tanto, muy parecido al anterior, al igual que las características que presentan los dos tipos de movimientos nacionales:

$$
\mathrm{AB} \rightarrow \mathrm{RB} \rightarrow \mathrm{BC} \rightarrow \mathrm{RI} \rightarrow \mathrm{FN} \rightarrow \mathrm{MO}
$$

El segundo modelo, que sería catalogado como "tardío" o "retardado" contempla los movimientos en los que la agitación nacionalista es previa a la revolución burguesa. No obstante, habrá que esperar hasta la consolidación de la revolución industrial y el capitalismo para que se produzca la transición entre las fases B y C, es decir, para que se consolide el nacionalismo como un movimiento de masas. Esto último puede producirse después de la organización del movimiento obrero o de una forma simultánea a este proceso:

$$
\begin{gathered}
\mathrm{AB} \rightarrow \mathrm{RB} \rightarrow \mathrm{RI} \rightarrow \mathrm{MO} \rightarrow \mathrm{BC} \rightarrow \mathrm{FN} \\
\mathrm{AB} \rightarrow \mathrm{RB} \rightarrow \mathrm{RI} \rightarrow \mathrm{MO} \rightarrow \mathrm{FN} \\
\searrow \mathrm{BC} \nearrow
\end{gathered}
$$

En este segundo modelo la consolidación nacional se produce de una forma tardía $\mathrm{y}$, en determinadas ocasiones, las reivindicaciones del movimiento obrero se encontrarían solapadas a las nacionales.

En el tercer modelo o "tipo insurreccional" la transformación del nacionalismo en un movimiento de masas se produce muy rápidamente y tiene un papel fundamental en la revolución burguesa, manifestándose por ejemplo en levantamientos armados contra la nación dominante. La potencia de estos movimientos es tal que a veces se produce antes la consolidación de la nación que la revolución industrial, pues el rápido desarrollo cultural y social así lo permiten:

$$
\begin{aligned}
& \mathrm{AB} \rightarrow \mathrm{BC} \rightarrow \mathrm{RB} \rightarrow \mathrm{FN} \rightarrow \mathrm{RI} \rightarrow \mathrm{MO} \\
& \mathrm{AB} \rightarrow \mathrm{BC} \rightarrow \mathrm{RB} \rightarrow \mathrm{RI} \rightarrow \mathrm{FN} \rightarrow \mathrm{MO}
\end{aligned}
$$

En el cuarto y último modelo propuesto por Hroch, que denomina "tipo desintegrado" vemos los ejemplos de aquellos movimientos nacionales cuyo periodo de agitación se produce una vez consolidados el capitalismo y un 


\section{Rodríguez Mesa - El Andalucismo}

sistema constitucional liberal, es decir, después de la revolución burguesa y la industrial. Por ello, en muchos casos estos movimientos nacionales tienen un paso muy tardío a la fase $\mathrm{C}$ o simplemente nunca llegan a triunfar entre las masas:

$$
\mathrm{RB} \rightarrow \mathrm{RI} \rightarrow \mathrm{AB} \rightarrow \mathrm{MO} \ldots \rightarrow\left[\mathrm{iBC}^{\mathrm{B}}\right]
$$

Una vez entendidos estos modelos de desarrollo, uno de los aspectos más interesantes del trabajo de Hroch es el hecho de que estudie una serie de movimientos nacionales que pone como ejemplos de estos. Por esta razón, como ya hemos explicado previamente, consideramos que puede ser muy útil aplicar sus propuestas teóricas al análisis del caso que nos ocupa, es decir, el del nacionalismo andaluz desde su aparición a principios del siglo XX hasta el estallido de la Guerra Civil.

\section{Los Orígenes del Andalucismo: La Fase A}

Sobre el andalucismo se han publicado numerosos trabajos que abarcan una multitud de temáticas, pudiéndose destacar aquellos relacionados con los antecedentes históricos de este movimiento, los que han tratado las iniciativas autonomistas surgidas durante la Segunda República y la Transición, pero, sobre todo, los que versan sobre la figura, pensamiento y obra de Blas Infante. Se trata de temas bien estudiados por autores como el ya fallecido Juan Antonio Lacomba (1988, 2008), Manuel Ruiz Romero (2010) o Manuel Hijano del Río (1997), cuyos trabajos destacan tanto por su variedad como por su enfoque en las características sociales y culturales del andalucismo.

En cualquier caso, todas las investigaciones sobre esta corriente política coinciden en situar sus raíces en el federalismo y el regionalismo, que se manifestarán de forma casi anecdótica desde la Restauración con iniciativas como el proyecto de Constitución Federalista de Andalucía que se presentó en Antequera en 1883. Sin embargo, este texto no debe ser interpretado en absoluto como nacionalista a pesar de reclamar la soberanía andaluza, que quedaría articulada bajo la forma de una democracia republicana en la que 
obtendrían un protagonismo fundamental valores como la libertad y la autonomía humana.

Habrá que esperar ya a principios del siglo XX para encontrarnos con la puesta en marcha de un movimiento que empezaría teniendo una inspiración regionalista, pero que rápidamente evolucionará hacia el nacionalismo. La iniciativa partiría de grupos vinculados al Ateneo de Sevilla, institución fundada en 1887, que estaban integrados por intelectuales y miembros de la pequeña burguesía, cuya relevancia social era minúscula dado el estado de subdesarrollo en el que se encontraba Andalucía (Lacomba Avellán, 1978). No obstante, esta élite, inspirada por corrientes como el krausismo, empezaría a interesarse por la cultura y las tradiciones regionales y no tardarían en ponerse en marcha algunos proyectos como la fundación de la Sociedad de Excursiones de Sevilla, la celebración de los Juegos Florales desde 1895 y la creación de la revista Bética en 1913 (Hurtado Sánchez, Ortíz Villalba y Cruz Artacho, 2013). Estos acontecimientos constituyen sin ninguna duda elementos fundamentales para delimitar el comienzo de la fase A del movimiento nacional que encontramos en las propuestas de Hroch, ya que nos encontramos con la configuración de unos grupos patrióticos que presentan rasgos similares a los de otros casos y propician el renacimiento cultural de la región. Esto último hay que entenderlo en un contexto tan concreto como es el de la España de principios del siglo XX, que es cuando ante la profunda crisis en la que se encuentra el país surgen corrientes como el regeneracionismo que, en muchos casos, fue acompañado de reivindicaciones regionalistas y nacionalistas. Desde esta perspectiva se entendía el centralismo como uno de los males que había conducido a la desastrosa situación de España junto con el caciquismo, por lo que no es de extrañar que el andalucismo rebasara rápidamente las dimensiones culturales para abrazar demandas de carácter político, produciéndose entonces la transición entre las fases A y B del modelo de Hroch.

\section{La Formación del Andalucismo como Movimiento Político (1914-1936): La Fase B}

Tal y como han venido señalando siempre los estudios sobre el nacionalismo andaluz, este debe su nacimiento y formulación a una figura fundamental 
como la de Blas Infante, quien en 1914 presenta ante el Ateneo de Sevilla su obra más importante, Ideal Andaluz. En esta reflexiona sobre numerosos asuntos, que van desde la existencia de Andalucía como región histórica con unas características culturales y una personalidad propia, hasta las causas de su atraso y la necesidad de que cuente con una dirección política que la saque de esta situación. Sin embargo, lo que por encima de todo habría que destacar es el análisis que realiza de la realidad social andaluza, en la que predominaban los jornaleros empobrecidos, pues la misma le lleva a considerar como algo complicado la generación de un sentimiento de pertenencia colectiva. Por ello, llegaría "a la conclusión de que Andalucía no puede crearse o reconstituirse, porque en ella no existe un pueblo posibilitado, mientras existan dichas circunstancias o capaz de ser consciente ni de ser libre" (Infante Pérez, 2010, p. 94). Para lograrlo sería fundamental la creación de una clase media campesina que contara con los medios suficientes para su prosperidad, es decir, con una cantidad de tierra suficiente (Infante Pérez, 2010).

Sin ninguna duda, el fundador del andalucismo demostró un enorme acierto tanto a la hora de interpretar cuáles eran los principales problemas que impedían el surgimiento de una identidad colectiva como al proponer soluciones al mismo, pues, como ya hemos explicado, el éxito del nacionalismo está casi siempre vinculado a su capacidad de conexión con las reivindicaciones sociales predominantes en la comunidad en la que surge y a la existencia de unos grupos patrióticos que lo lideren.

La presentación del Ideal Andaluz supone entonces la primera manifestación del andalucismo desde un punto de vista político, pero rápidamente se sucederían otras actividades como la fundación, también por parte de Blas Infante, del Centro Andaluz de Sevilla en octubre de 1916, y de la revista Andalucía, cuyo primer número fue publicado en junio de ese mismo año (Cruz Artacho, 2016). Esta se convertiría en el altavoz de la causa regionalista, tal y como quedó expresado en su programa inaugural, en el que se proponía una sección dedicada a la información política en la cual se recogerían los actos de promoción de esta corriente:

En la sección de dirección política defenderemos todos nuestros ideales de este orden, principalmente los de heterogeneidad en la organización y autonomía regional y municipal, unión de Andalucía y 
de los pueblos ibéricos y solidaridades internacionales, la acción política en sus diferentes órdenes, de pedagogía, engrandecimiento de las poblaciones, higiene, perfección de los servicios públicos, etc., etc.; estado de la llamada actualmente política en las diferentes localidades, y, finalmente, estado de nuestra propaganda.

$\mathrm{Y}$, por último, dedicaremos otra sección de nuestra revista a dar a conocer los actos que hayamos realizado en cumplimiento de nuestros fines. Esta sección nos parece la más importante. Hablar poco y hacer mucho ${ }^{3}$.

La creación de ambas instituciones es un ejemplo claro de esta transición del andalucismo a la fase B, pues demuestra la existencia de una voluntad clara de pasar a la acción política, tal y como es posible observar en el protagonismo que asumieron a la hora de preparar la convocatoria de la Asamblea de Ronda en 1918. Esta sería organizada por el Centro Andaluz, mientras que la revista Andalucía se encargaría de la divulgación del manifiesto de adhesión a los principios de un movimiento totalmente inspirado en el Ideal Andaluz:

Andaluces:

Ha llegado la hora de que Andalucía, la Región que siempre fue más civilizada de España, y, en ocasiones, la Nación más civilizada del Mundo, despierte y se levante para salvarse a sí misma y salvar a España de la vergonzosa decadencia a que han sido arrastradas durante varios siglos por los Poderes centrales, presididos por hombres inconscientes o malvados (...).

La dignidad de los andaluces exige la creación en Andalucía de un pueblo consciente y capacitado; exige el concluir de una vez, sea como sea, con los caciques y sus protectores los oligarcas; hay que evitar continúe siendo Andalucía el país del hambre y de la incultura, «la tierra más alegre de los hombres más tristes del mundo». Tenemos que tomar la tierra dé aquellos que no la cultivan, para entregarla a los que deseen trabajarla, evitando con esto la espantosa emigración. Tenemos que educar urgentemente una generación de adultos, una generación de padres que concluyan en sus hijos las generaciones de analfabetos $(\ldots)^{4}$. 
A través de este manifiesto se ponían por primera vez unas bases políticas del andalucismo que insistían en la obtención de la autonomía no como un fin en sí mismo, sino como un medio para lograr el desarrollo regional, además de aprobarse unos símbolos que hoy son institucionales y que demuestran la voluntad de construir una identidad colectiva (Ruiz Romero, 2007). Sin embargo, no habrá que esperar mucho para que, a raíz de los acontecimientos internacionales y por mimetismo con las demandas que aparecían en otros lugares de España como Cataluña o el País Vasco, el movimiento abrazara unas posturas nacionalistas. De esta forma, nos encontraremos con una notable influencia del principio de las nacionalidades de Wilson en el pensamiento de Blas Infante, quien más tarde se retractaría del mismo (Acosta Ramírez y Cruz Artacho, 2015). El mejor ejemplo de ello será el manifiesto aprobado en la Asamblea de Córdoba el año siguiente, en el cual se adopta un lenguaje mucho más crítico y rupturista con el Estado y se ofrece un extenso programa de propuestas políticas para convertir Andalucía, definida como una "realidad nacional", en una "Democracia Soberana y Autónoma", tal y como se propuso en el ya citado proyecto de Constitución Federalista de $1883^{5}$.

Esta actividad tenía como finalidad dotar al andalucismo de unos principios políticos sólidos a imitación de lo que, por ejemplo, había sucedido en Cataluña con el establecimiento de las Bases de Manresa en 1892. Sin embargo, los andalucistas se encontrarían con ciertos problemas en la difusión de las reivindicaciones nacionalistas de los que el propio Infante era consciente, tal y como advertía en el Ideal Andaluz, como el hecho de que sus bases sociales no trascendieran de sectores de la pequeña burguesía, profesionales liberales, comerciantes, industriales e intelectuales, siendo por tanto poco representativas de la sociedad andaluza. Esto queda reflejado en la composición de las estructuras de los distintos centros andaluces fundados como el de Sevilla, el de Córdoba o el de Jaén, donde apenas se encuentran casos de jornaleros u obreros entre sus miembros (Cruz Artacho, 2017).

Por otro lado, podríamos decir que el andalucismo, atendiendo a las propuestas de Hroch, llegaría demasiado tarde para lograr su éxito a diferencia con lo ocurrido en Cataluña. De esta manera, podríamos encuadrar el movimiento nacional catalán en el tipo tardío, ya que en su caso 
se vivió la transición entre las fases B y C después de haberse consolidado las revoluciones burguesa e industrial y de forma paralela a la aparición del movimiento obrero. En cambio, este último ya se encontraba bien asentado en Andalucía, sobre todo en su variante anarquista, y sus demandas centradas en el reparto de la tierra y la mejora de las condiciones de trabajo de los jornaleros ya fueron formuladas mucho antes de que lo hicieran los andalucistas (González de Molina Navarro y Caro Cancela, 2001). Estos, además, no se propusieron seriamente la creación de partidos políticos propios, sino que se limitarían a tratar de lograr confluencias con republicanos y socialistas en algunas candidaturas electorales, intentando conectar sobre todo con las clases populares aunque con pobres resultados (Cruz Artacho, 2017).

La ausencia de partidos estables y modernos sería en definitiva otro de los obstáculos para que el andalucismo triunfara como movimiento político de masas, ya que estos se revelan indispensables para alcanzar la fase $\mathrm{C}$. Estos habrían facilitado la construcción de una conciencia nacional mediante la consideración de este objetivo como un elemento esencial que, además, habría pasado a ser uno de los ejes del debate público. Este error volvería a repetirse una vez acabada la dictadura de Primo de Rivera, que supuso un paréntesis en la vida política andaluza al igual que en la del resto del país. De hecho, el movimiento volvería a reactivarse a partir de los antiguos Centros Andaluces, que desde 1931 pasarían a constituir la nueva Junta Liberalista de Andalucía, una organización con fines similares y que, por tanto, no traería consigo novedades interesantes, pues seguía, tal y como defiende Cruz Artacho (2017), "sin perseguir ni fomentar la constitución de partido político alguno, promoviendo un movimiento de concienciación y acción andaluza de carácter interclasista y fomentando una dinámica de solidaridad en la consecución del objetivo común". Sobre este problema también reflexionó Juan Antonio Lacomba (1980, p. 76), quien coincide explicando que:

(...) el problema andaluz, pese a este paralelismo histórico con los demás regionalismos, estribó en la falta de un arraigo social amplio y profundo de la conciencia "andalucista", así como la carencia de partidos políticos de "obediencia regional" que canalizaran el 
movimiento. Todos estos fueron déficits que quedaron bien patentes en la "problemática autonomista andaluza" durante la II República.

Las iniciativas de la Junta Liberalista estarían enfocadas igualmente a la consecución de un objetivo político, la obtención de la autonomía para Andalucía, para el cual la coyuntura se presentaba mucho más propicia de lo que había sido durante el reinado de Alfonso XIII. Sin embargo, los nacionalistas andaluces se encontrarían con fuertes reticencias por parte de las diputaciones para sacar adelante este proyecto, pues salvo la de Sevilla, presidida por el socialista Hermenegildo Casas, ninguna de ellas mostró interés en el mismo. Lo mismo ocurriría con otras instituciones y los representantes electos, que consideraban prioritarios otros problemas, como la cuestión agraria, frente a este asunto que ciertamente despertaba poca movilización popular a pesar de la insistencia de la Junta Liberalista. De hecho, no será hasta enero de 1933 cuando se reúnan los representantes institucionales, políticos y sindicales de Andalucía en la Asamblea de Córdoba, donde se presentó una ponencia elaborada por un comité en el que estaban presentes tanto Hermenegildo Casas como Blas Infante (Barragán Moriana, 2014). Esta propuesta llevaría por título Anteproyecto de Bases para el Estatuto de Autonomía de Andalucía y en ella se recogían los principios en los que debería basarse la redacción de un estatuto regional ${ }^{6}$. Sin embargo, tanto las reticencias de los presentes en esta asamblea, con una oposición notable por parte de los representantes de las provincias orientales, como el inicio del bienio conservador impedirían que se pusiera en marcha finalmente esta iniciativa clave en el programa político del andalucismo.

Sin embargo, lo peor estaba por llegar, ya que este movimiento se vería totalmente anulado al comenzar la Guerra Civil, pues, además de no haberse consolidado ni haber logrado algunos de sus objetivos esenciales, se vería privado de su principal ideólogo. De esta forma, Blas Infante sería asesinado por los golpistas el 11 de agosto de 1936, nada más empezar la guerra, lo que acabaría truncando el desarrollo y las aspiraciones del andalucismo, que tendría que esperar hasta el final de la dictadura para reaparecer en la escena política, pero ya con un contexto bastante distinto a aquel en el que nació. 


\section{Conclusiones}

Por medio de este trabajo hemos tratado de hacer un recorrido por la historia del andalucismo desde sus orígenes hasta el estallido de la Guerra Civil con la intención de aplicar las premisas de la teoría de Miroslav Hroch, que ha aportado a la historiografía del nacionalismo una perspectiva de enorme interés. Esto se debe a que, a diferencia de los autores de los que hemos hablado en el segundo apartado, Hroch no se centra en los orígenes del nacionalismo, sino en la evolución diacrónica que suelen seguir los movimientos patrióticos y los factores que favorecen su éxito, presentando distintos modelos de desarrollo. De la misma forma, de este autor también podríamos destacar la realización de un análisis comparativo de distintos casos presentes en países de Europa central y oriental, con el fin tanto de conocer los puntos en común que presentan como sus diferencias en función de determinados factores.

En este caso hemos aplicado las propuestas de Hroch al andalucismo, un movimiento nacional que no logró desarrollarse ni alcanzar la fase $\mathrm{C}$, extendiéndose a las masas, algo que a nuestro juicio le ha llevado a encontrarse actualmente en un estado de letargo, encajando por tanto claramente en el tipo desintegrado. Es por ello que no debe extrañarnos su situación, que es la de un movimiento político poco relevante a pesar de que gran parte de sus reivindicaciones originales se hayan materializado. De hecho, aunque Andalucía siga encontrándose con algunos problemas importantes y un nivel de desarrollo algo menor al del conjunto de España, los niveles de bienestar son más que aceptables y, al mismo tiempo, se dispone de un alto nivel de autonomía regional. Sin embargo, a diferencia de lo que ocurre en los casos de Europa oriental y en los de aquellos movimientos nacionales que han obtenido una mayor influencia dentro del Estado, el andalucismo, además de no contar con esos factores que hemos citado como fundamentales, como la existencia de una burguesía potente que impulsara el proceso de creación de una identidad colectiva, tampoco ha disfrutado de un elemento que contribuye en gran medida a favorecerla: una lengua propia.

Con esto último queremos decir que el hecho de disponer de una lengua ayuda enormemente a la hora de afrontar la construcción nacional, al 


\section{Rodríguez Mesa-El Andalucismo}

constituir un importante rasgo diferencial. A pesar de la existencia de ciertas peculiaridades culturales con respecto al conjunto del Estado del que forma parte, Andalucía no dispone de ella, algo que en cambio sí ocurre en Cataluña, el País Vasco, Galicia, al igual que en los casos que utiliza Hroch como ejemplo en su principal trabajo: fineses, checos, eslovacos, noruegos, flamencos, estonios, lituanos y daneses. No obstante, es necesario aclarar que se han producido casos de movimientos nacionales exitosos en los que la lengua no ha desempeñado un papel determinante por haberse visto sobrepasada por la del imperio o Estado del que han formado parte. El caso irlandés sería un claro ejemplo de ello, pues, aunque su movimiento nacional reivindicara el valor del gaélico, lo cierto es que este no lograría imponerse como lengua común frente al inglés. Por esta razón, resulta de especial interés hacer análisis comparativos de los distintos nacionalismos partiendo de las premisas de Hroch, pues todos y cada uno de ellos pueden presentar una serie de rasgos particulares que los hagan diferentes, aunque muestren evoluciones similares. Asimismo, sería necesario plantearse la validez de sus propuestas en casos fuera del ámbito donde se han circunscrito, pues puede que fuera de Europa se presenten esquemas distintos.

Volviendo al tema que nos ocupa podemos decir que, en definitiva, el andalucismo, desde su propia formulación como corriente política, se mostraría consciente de sus graves limitaciones, tal y como advirtió Blas Infante. Además, su programa no contó con apenas partidarios en su periodo de gestación y, cuando estuvo en el centro del debate político de la Transición, fue asumido por la mayoría de los partidos establecidos en Andalucía, pero no desde una óptica nacionalista. El PSOE lograría hacerse con la hegemonía en la región hasta nuestros días, consiguiendo presentarse como la fuerza que luchó por la autonomía y el progreso, llevando a las formaciones explícitamente andalucistas a una posición de irrelevancia y retroceso.

\section{Notas}

1 “Acto de defunción en blanco y verde", ABC Sevilla, 12 de septiembre de 2015, p. 39.

${ }^{2}$ Siendo cada una de las siglas lo siguiente:

AB: transición entre las fases A y B

$\mathrm{RI}$ : comienzo de la revolución industrial 
RB: revolución burguesa

$\mathrm{BC}$ : transición entre las fases $\mathrm{B}$ y C

FN: formación de la nación moderna

MO: aparición del movimiento obrero

3"Nuestro programa", Andalucía, n 1, junio de 1916, p. 3.

4 "Por la unión de las provincias andaluzas", Andalucía, no 8, enero de 1917, p. 3.

5 "Córdoba 1919-1979: LX aniversario del manifiesto nacionalista (texto resumido)", Andalucía Libre, marzo de 1979.

${ }^{6}$ Sevilla, Archivo de la Diputación Provincial, El Proceso Autonómico Andaluz durante la II República en el Archivo de la Diputación de Sevilla, 1931-1936, legajo 550, carpeta II.F

\section{Referencias}

\section{Fuentes Primarias}

"Acto de defunción en blanco y verde", $A B C$ Sevilla, 12 de septiembre de 2015 , p. 39.

“Córdoba 1919-1979: LX aniversario del manifiesto nacionalista (texto resumido)", Andalucía Libre, marzo de 1979.

"Nuestro programa", Andalucía, no 1, junio de 1916, p. 3.

"Por la unión de las provincias andaluzas", Andalucía, no 8, enero de 1917, p. 3.

Sevilla, Archivo de la Diputación Provincial, El Proceso Autonómico Andaluz durante la II República en el Archivo de la Diputación de Sevilla, 1931-1936, legajo 550, carpeta II.F.

\section{Fuentes Bibliográficas}

Acosta Ramírez, F., y Cruz Artacho, S. (2015). Del regionalismo al nacionalismo por «la fuerza bruta de las guerras». El impacto de la Primera Guerra Mundial en el pensamiento de Blas Infante. Historia y Política, 33, 75-98.

Álvarez Junco, J. (2016). Dioses útiles: naciones y nacionalismo. Barcelona: Galaxia Gutenberg.

Anderson, B. (1993). Comunidades imaginadas. México DF: Fondo de Cultura Económica. 
Barragán Moriana, A. (2014). La Asamblea de Córdoba de 1933 y el Anteproyecto de Bases para el Estatuto de Autonomía de Andalucía. Sevilla: Centro de Estudios Andaluces y Consejería de Presidencia de la Junta de Andalucía.

Breuilly, J. (1993). Nationalism and the State. Nueva York: Manchester University Press.

Centro de Análisis y Documentación Política y Electoral de Andalucía (2018). Estudio General de Opinión Pública de Andalucía. Edición EGOPA Invierno 2018. Granada: Universidad de Granada.

Cruz Artacho, S. (2011). El año que vivimos intensamente: de la movilización del 4 de diciembre al Pacto de Antequera. Andalucía en la historia, 32, 74-78.

Cruz Artacho, S. (2016). Andalucía: de región a nación. El andalucismo histórico (I) 1907-1916. Sevilla: Centro de Estudios Andaluces y Consejería de Presidencia y Administración Local de la Junta de Andalucía.

Cruz Artacho, S. (2017). Entre la Europa wilsoniana y el discurso bolchevique. El andalucismo histórico (II). 1916-1936. Sevilla: Centro de Estudios Andaluces y Consejería de Presidencia y Administración Local de la Junta de Andalucía.

Díaz Arriaza, J., y Ruiz Romero, M. (1991). El proceso autonómico de Andalucía durante la II República: nuevas aportaciones. Sevilla: Fundación Blas Infante.

Gellner, E. (2001). Naciones y nacionalismo. Madrid: Alianza Editorial.

González de Molina Navarro, M. L., y Caro Cancela, D. (2001). La utopía racional: estudios sobre el movimiento obrero andaluz. Granada: Universidad de Granada.

Hijano del Río, M., y Ruiz Romero, M. (1997). El pacto autonómico de Antequera (4 diciembre de 1978): un documento para la historia de Andalucía. Sevilla: Instituto Andaluz de Administración Pública.

Hroch, M. (1985). Social preconditions of national revival in Europe. Cambridge: Cambridge University Press.

Hroch, M. (1994). La construcción de la identidad nacional: del grupo étnico a la nación moderna. Revista de Occidente, 161, 45-60.

Hroch, M. (2001). La naturalesa de la nació. Catarroja: Editorial Afers. 
Hurtado Sánchez, J., Ortíz Villalba, J., y Cruz Artacho, S. (2013). Bética y el regionalismo andaluz. A propósito del Centenario. Sevilla: Centro de Estudios Andaluces y Consejería de Presidencia de la Junta de Andalucía.

Infante Pérez, B. (2010). Ideal Andaluz. Sevilla: Centro de Estudios Andaluces y Consejería de Presidencia de la Junta de Andalucía.

Lacomba Avellán, J.A. (1978). Pequeña burguesía y revolución regional: el despliegue del regionalismo andaluz. Revista de estudios regionales, 1, 65-86.

Lacomba Avellán, J.A. (1980). La II República española y las autonomías. El caso andaluz. Revista de Estudios Regionales, II(extraordinario).

Lacomba Avellán, J.A. (1988). Regionalismo y autonomía en la Andalucía contemporánea (1835-1936). Granada: Caja General de Ahorros y Monte de Piedad.

Lacomba Avellán, J.A. (2008). Blas Infante y el andalucismo. Granada: Caja Granada, Obra Social.

Ruiz Romero, M. (2007). Los símbolos institucionales de Andalucía (19181982): De la marginalidad al pleno reconocimiento institucional. En A. Rodríguez Patrón (coord.), Tendencias actuales en las Relaciones Públicas (pp. 683-701). Sevilla: Asociación de Investigadores en Relaciones Públicas.

Ruiz Romero, M. (2010). Blas Infante Pérez, 1885-1936. Sevilla: Centro de Estudios Andaluces.

Ruiz Romero, M. (2018). La dialéctica andalucismo/socialismo en el contexto del sistema de partidos de la Transición. La emergencia nacionalista y la asunción estratégica de sus aportaciones por el PSOE (1977-1982). Pasado y Memoria. Revista de Historia Contemporánea, 17, 81-102.

Smith, A.D. (1997). La identidad nacional. Madrid: Trama Editorial.

Thiesse, A.M. (2010). La creación de las identidades nacionales. Madrid: Ézaro Ediciones.

Tilly, C. (1975). The Formation of National States in Western Europe. Princeton: Princeton University Press.

Weber, E. (1976). Peasants into Frenchmen. Stanford: Stanford University Press. 
Cristian Rodríguez Mesa es investigador predoctoral de la Universidad de Cádiz por el Plan Propio de Investigación, España.

Dirección de contacto: Avenida del Ejército 6, Edificio Plaza, $3^{\circ} \mathrm{C}$, El Puerto de Santa María (Cádiz). CP 11500. Email: cristian.rodriguez@uca.es 